\title{
Eocuma orbiculatum sp. nov. (Crustacea, Cumacea, Bodotriidae) from Korean waters
}

\author{
Sung-Hyun Kim', Chang-Mok Lee², Young-Hyo Kim' \\ I Department of Biological Sciences, Dankook University, Cheonan 31116, South Korea 2 Hanmin High \\ School, Paju 10955, South Korea \\ Corresponding author: Young-Hyo Kim (yhkim@dankook.ac.kr)
}

Academic editor: S. Gerken | Received 8 October 2019 | Accepted 6 January 2020 | Published 10 February 2020

http://zoobank.org/C3621642-DACB-4377-AE05-B2A90170D940

Citation: Kim S-H, Lee C-M, Kim Y-H (2020) Eocuma orbiculatum sp. nov. (Crustacea, Cumacea, Bodotriidae) from Korean waters. ZooKeys 910: 79-91. https://doi.org/10.3897/zookeys.910.47143

\begin{abstract}
A new species of Cumacea belonging to the genus Eocuma Marcusen was collected from the South Sea of Korea. This new species resembles E. amakusense Gamô, E. hilgendorfi Marcusen, and E. latum Calman in having a pair of well-developed dorso-lateral carinae on the flat carapace and similar setae pattern on the telson. The new species, however, is easily distinguished from its congeners by the pattern of dorso-lateral carina and lacking lateral horns on the carapace. The adult male of this new species is fully described. A key to the Korean Eocuma species is also provided.
\end{abstract}

\section{Keywords}

Bodotriidae, Cumacea, Eocuma, key, Korea, new species, taxonomy

\section{Introduction}

The family Bodotriidae Scott, 1901 contains two subfamilies: Bodotriinae Scott, 1901 and Vaunthompsoniinae Sars, 1878 (Haye 2007). The subfamily Bodotriinae is composed of 14 genera and it is characterized by having exopods on the maxilliped 3 and pereopod 1 in both sexes, and five pairs of pleopods in males of most genera (Haye 2007; WoRMS 2019). Among the 14 genera, Eocuma Marcusen, 1894 is the fourth most speciose genus, after Bodotria Goodsir, 1843, Cyclaspis Sars, 1865, and Iphinoe Bate, 1856. To date, 31 species are known in the genus Eocuma (Haye 2007; WoRMS

Copyright Sung-Hyun Kim et al. This is an open access article distributed under the terms of the Creative Commons Attribution License (CC BY 4.0), which permits unrestricted use, distribution, and reproduction in any medium, provided the original author and source are credited. 
2019), of which three have been reported from Korea: Eocuma amakusense Gamô, 1967 (Kim et al. 2017), E. cf. hilgendorfi Marcusen, 1894 (Park et al. 1998), and E. latum Calman, 1907 (Kim et al. 2017). In this study, we describe and illustrate a new species of Eocuma from Korean waters. A key to the Korean species of the genus Eocuma is also provided.

\section{Material and methods}

The specimen was collected using a light-trap (Holmes and O'Connor 1988; Kim 1992) from shallow water at Hangdong Port, Wando-gun, Jeollanam-do, Korea. The collected specimen was fixed in 70-80\% ethanol, moved to the laboratory, and stored in $95 \%$ ethanol. The specimen was identified with a stereomicroscope (Model SZX12; Olympus, Japan). The photographs of the whole body were taken with a microscope equipped a digital camera (eXcope T500; DIXI Science, Korea) and complemented by Helicon Focus software (Model Helicon Focus; Helicon Soft Ltd., Kharkov, Ukraine). The body length was measured from the anterior tip of the carapace to the posterior end of the pleonite 6 . Lengths of the appendages were measured along the midline of each appendage. Drawing of the whole body was performed under a stereomicroscope (Model SZX12) with a drawing tube. Later, the sample was transferred to glycerin to be dissected under a stereomicroscope (Model SZX12). Drawing of the appendages were performed with a light microscope (Model BX51; Olympus, Japan). Photographs of the carapace surface were taken using a scanning electron microscope. Type specimen was deposited at the National Institute of Biological Resources (NIBR), in Incheon, Korea.

\section{Taxonomy}

\section{Genus Eocuma Marcusen, 1894}

Type species. Eocuma hilgendorfi Marcussen, 1894.

Diagnosis. Carapace may appear laterally compressed anteriorly or posteriorly in dorsal view; may be oviform posteriorly; may have dorsal median carina, dorso-lateral carinae, lateral carinae and/or lateral horns. Antenna 1 with basal article of the peduncle arcuate or straight, as long as or shorter than the other two articles combined. Maxilliped 3 basis geniculate, arcuate or straight, extended dorso-distally over ischium beyond the articulation of the ischium and merus. First pereonite visible only above lateral midline or invisible. Pereonite 2 variable in width with respect to other pereonites; may have ventro-lateral expansion overriding pereonite 3, carapace and pereonite 3 or not overriding other somites. Basis of pereopod 1 distally produced beyond insertion of ischium. Pereopod 2 without ischium; dactylus longer than propodus. Uropod peduncle much shorter than pleotelson or rami. Uropod endopod uniarticulate. Uropod exopod with proximal article shorter than distal one. Males with five pairs of pleopods. 
Remarks. Eocuma was considered similar to Mossambicuma Day, 1978, but could be distinguished by carapace shape and projection on the basis of the pereopod 1 . Haye (2007) demonstrated, however, Mossambicuma to be a synonym for Eocuma, since E. muradianae Petrescu, 1998 also lacks the projection on the basis of pereopod 1 and many other species in Eocuma lack lateral horns. Haye (2007) supported these observations by analyzing character evolution of the family Bodotriidae, including the genus Eocuma. Korean species reported as Eocuma, including this new species, have morphological characteristics that correspond to the universal characteristics of Eocuma diagnosed by Haye (2007).

Species composition. Eocuma aculeatum Day, 1978; E. affine Calman, 1904; E. agrion Zimmer, 1914; E. amakusense Gamô, 1967; E. bacescui Petrescu, 2003; E. cadenati Fage, 1950; E. calmani Fage, 1928; E. carinocurvum Corbera, Tirado \& Martin, 2005; E. cochlear Le Loeuff \& Intes, 1972; E. dimorphum Fage, 1928; E. dollfusi Calman, 1907; E. elongatum (Day, 1978); E. ferox (Fischer, 1872); E. foveolatum Day, 1978; E. gorgasiae Mühlenhardt-Siegel, 1996; E. hilgendorfi Marcusen, 1894; E. kempi Kurian, 1954; E. lanatum Le Loeuff \& Intes, 1972; E. latum Calman, 1907; E. longicorne Calman, 1907; E. muradianae Petrescu, 1998; E. petrescui Patel, Haye \& Kornfield, 2003; E. rosae Corbera \& Galil, 2007; E. sarsii (Kossmann, 1880); E. spiniferum Gamo, 1976; E. stelliferum Calman, 1907; E. striatum Kurian \& Radha Devi, 1983; E. taprobanicum Calman, 1904; E. travancoricum Kurian, 1951; E. victoriae (Mühlenhardt-Siegel, 2003); and E. winri Day, 1978.

\section{Eocuma orbiculatum sp. nov.}

http://zoobank.org/478C96E3-96B6-4E3F-90DE-81874690FF3B

Figures 1-5

Korean name: Dung-geun-nap-jak-ol-chaeng-i-sae-u, new

Type material. Holotype: adult male, $11.92 \mathrm{~mm}$, NIBRIV0000812748, Hangdong Port, Sedong-ri, Wando-gun, Jeollanam-do, Korea, 34²3'38.2"N, 126 $50^{\prime} 29.3^{\prime \prime E}$, Y.H. Kim, 22 June 2008.

Description. Holotype, adult male, NIBRIV0000812748.

Length: $11.92 \mathrm{~mm}$, excluding uropods. Carapace (Figs 1A, B, 2A-C, 3A, B) 0.26 $\times$ body length, $1.4 \times$ width; surface covered with minute shallow pits; lateral margins of carapace, pereon, and pleon lamellate; pseudorostrum a little in advance of antero-lateral horns with rounded apices, without lateral horns; dorsal median carina extending from eye-lobe to posterior margin of carapace; a pair of dorso-lateral carinae well-marked, extending from near the antero-lateral horns to $4 / 5$ way of carapace; ocular lobe (Fig. 2B) with 3 lenses. Pereon (Fig. 2A, B) $0.7 \times$ carapace. Pleon (Fig. 2A) $1.3 \times$ cephalothorax.

Antenna 1 (Fig. 2D) peduncle 3-articulate; article 1 flattened, broader at base, with several hair-like, 10 short simple, and 4 complex pedunculate setae; article $20.4 \times$ article 1 , with 2 short simple and 3 complex pedunculate setae; article $31.4 \times$ article 2 , with 2 complex pedunculate setae distally. Main flagellum 3-articulate; article 1 with 


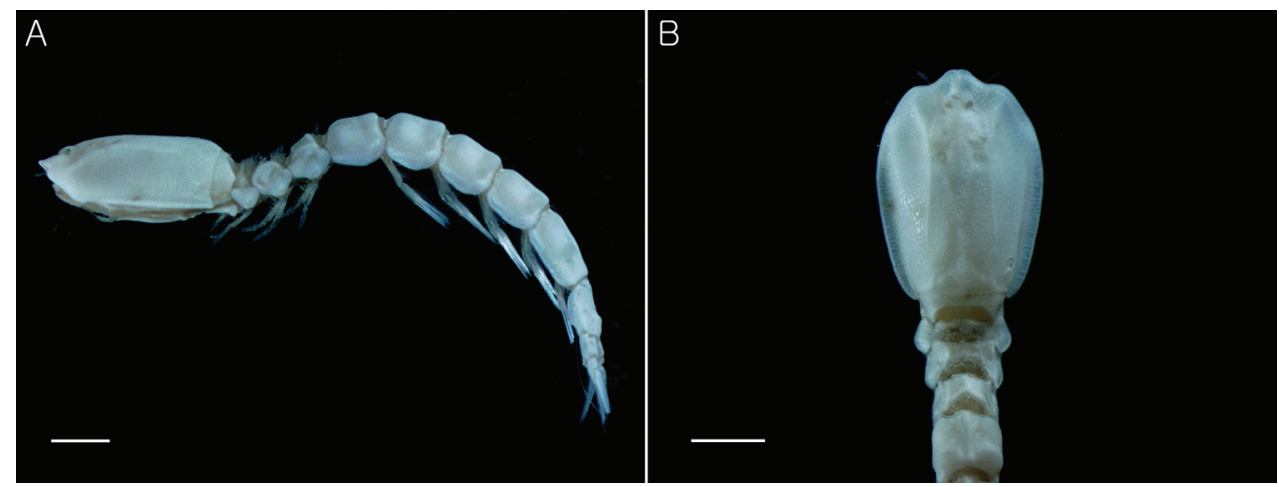

Figure I. Eocuma orbiculatum sp. nov., holotype, adult male, $11.92 \mathrm{~mm}$. A Lateral view B cephalothorax, dorsal view. Scale bars: $1.0 \mathrm{~mm}(\mathbf{A}, \mathbf{B})$.

3 aesthetascs; article 2 with 1 aesthetasc; article 3 with 2 simple setae, 1 long simple seta, and 1 aesthetasc terminally. Accessory flagellum minute, with 1 short simple and 2 complex pedunculate setae.

Antenna 2 (Fig. 2A, E) extending beyond pleotelson; peduncle 5-articulated; article 2 with 1 or 2 plumose setae; articles $4-5$ with numerous simple setae, article 5 with 2 complex pedunculate setae dorso-distally.

Left mandible (Fig. 2F) with row of several hair-like and 14 setae; incisor with 4 teeth; lacinia mobilis with 3 teeth. Right mandible (Fig. 2G) with row of several hairlike and 14 setae; incisor with 2 teeth.

Maxilla 1 (Fig. 2H) outer endite with a few hair-like setae medially, 1 simple seta laterodistally, 13 stout simple setae terminally; inner endite with several hair-like setae medially, a few hair-like setae laterodistally, 4 microserrate and 2 stout tricuspid setae terminally; palp broken, with 2 setae.

Maxilla 2 (Fig. 4A) broad endite with several hair-like, 26 plumose, and $3 \mathrm{mi}$ croserrate setae medially, 6 plumose, 25 simple, 11 microserrate, 2 plumo-microserrate, and 1 pappo-serrate setae terminally; outer endite with a few hair-like and 7 stout microserrate setae terminally; inner endite with 6 stout microserrate setae terminally.

Maxilliped 1 (Fig. 4B) basis with a few hair-like setae mediodistally, 1 long plumose seta on medial distal corner, 13 simple setae on lateral surface, a few hair-like setae laterodistally; medial lobe with 1 coupling hook and 8 plumo-microserrate setae medially, 3 stout simple setae on medial distal surface, 1 plumose and 2 stout simple setae terminally; ischium absent; merus with a few hair-like, 8 short simple, and 2 long plumose setae; carpus $2.1 \times$ merus, with 21 plumose and 8 stout setae medially, numerous hair-like setae on lateral surface, 1 short simple seta laterally, 1 long plumose seta on laterodistal corner; propodus $0.5 \times$ carpus, with a few hair-like, 20 plumose, 1 simple, 1 microserrate, and 1 plumo-microserrate setae medially, a few hair-like and 3 short simple setae medially, 3 long plumose setae distally; dactylus $0.7 \times$ propodus, a few hair-like and 2 simple setae medially, 2 stout microserrate setae terminally. 


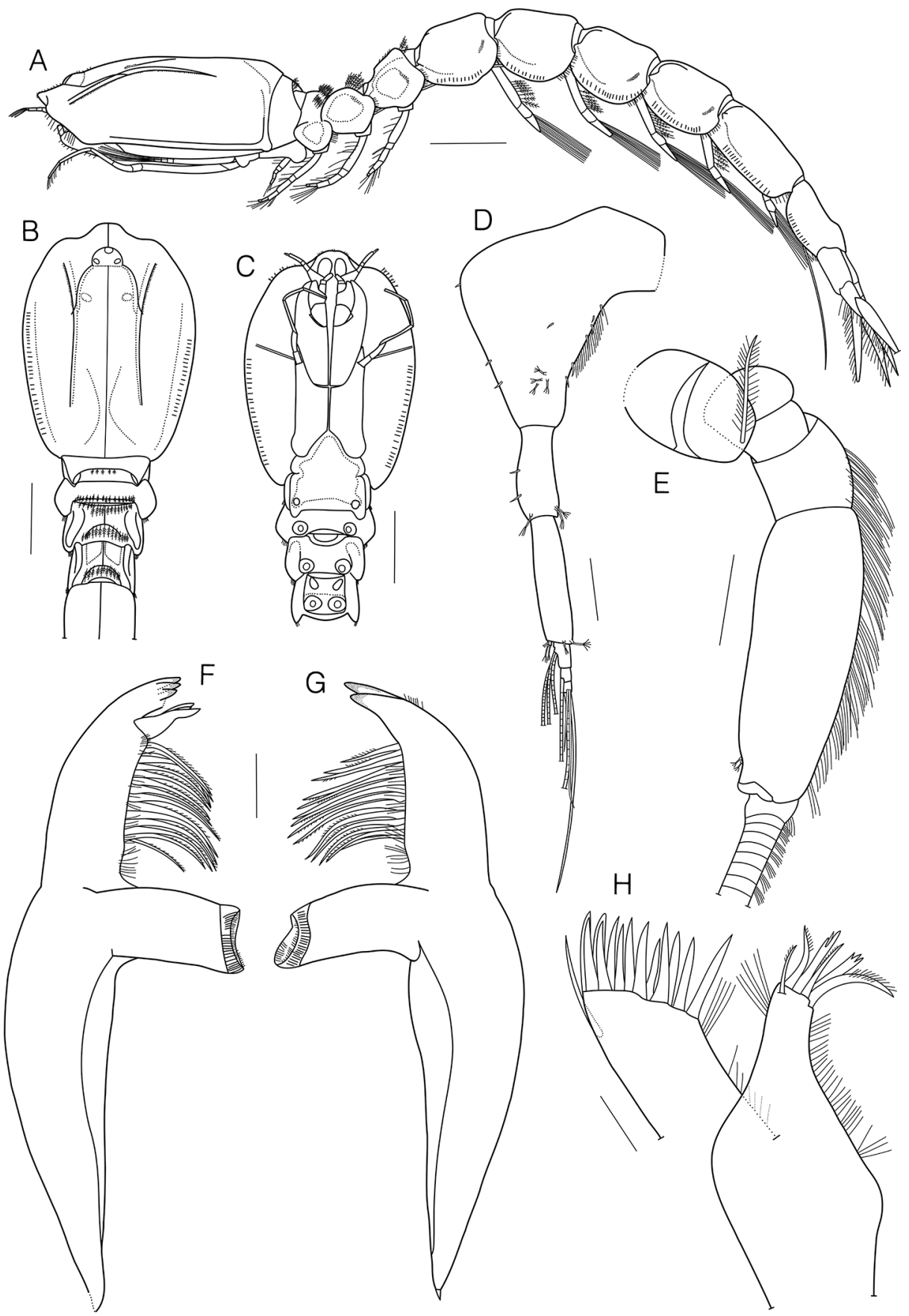

Figure 2. Eocuma orbiculatum sp. nov., holotype, adult male, $11.92 \mathrm{~mm}$. A Habitus, lateral view B cephalothorax, dorsal view $\mathbf{C}$ cephalothorax, ventral view $\mathbf{D}$ antenna $1 \mathbf{E}$ antenna $2 \mathbf{F}$ left mandible $\mathbf{G}$ right mandible $\mathbf{H}$ maxilla 1. Scale bars: $1.0 \mathrm{~mm}(\mathbf{A}-\mathbf{C}), 0.2 \mathrm{~mm}(\mathbf{D}), 0.1 \mathrm{~mm}(\mathbf{C}, \mathbf{E}, \mathbf{F}), 0.05 \mathrm{~mm}(\mathbf{G})$. 

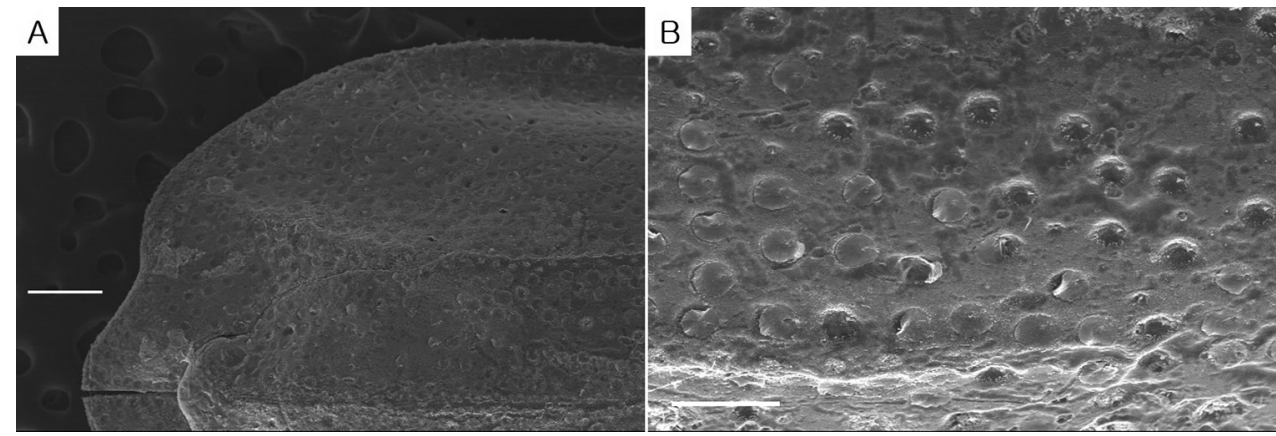

Figure 3. Eocuma orbiculatum sp. nov., holotype, adult male, $11.92 \mathrm{~mm}$. A, B Carapace, dorsal view. Scale bar: $250 \mu \mathrm{m}(\mathbf{A}), 125 \mu \mathrm{m}(\mathbf{B})$.

Maxilliped 2 (Fig. 4C) basis $1.4 \times$ remaining articles combined, with numerous hair-like setae medially, 2 short simple and 4 long plumose setae mediodistally, numerous hair-like setae on lateral surface, 18 short simple and several hair-like setae laterally; ischium short, unarmed; merus $0.3 \times$ basis, with 1 long plumose seta on medial distal surface, several hair-like and 4 short simple setae on lateral surface, a few hair-like and 1 short simple setae laterally; carpus $0.7 \times$ merus, with 3 plumose and 4 plumomicroserrate setae medially, several hair-like setae on lateral surface, 1 short simple seta laterally; propodus $0.8 \times$ carpus, with 2 microserrate, 10 plumo-microserrate, and 1 plumose setae medially, several hair-like setae on lateral surface, 2 long plumose setae laterally; dactylus $0.5 \times$ propodus, with 1 long simple seta on lateral surface, 2 simple, 1 microserrate, and 1 stout microserrate setae terminally.

Maxilliped 3 (Fig. 4D) basis $1.4 \times$ remaining articles combined, with numerous hair-like setae medially, 2 plumose setae on medial distal corner, numerous hair-like setae on medial surface and lateral margin, 1 short simple seta with subterminal setules laterally; produced distally to border between merus and carpus, with 1 short simple and 14 plumose setae medially, 5 short simple setae with subterminal setules laterally; ischium $0.2 \times$ basis, with several hair-like and 9 plumose setae medially; merus subequal to ischium, with several hair-like and 1 plumose setae medially; carpus $0.5 \times$ merus, with 1 plumose seta medially; propodus $1.1 \times$ carpus, with 1 short simple and 7 plumose setae medially, 1 short simple seta laterodistally; dactylus $0.8 \times$ propodus, with a few hair-like setae medially, 1 short simple and 2 hair-like setae laterally, $5 \mathrm{mi}$ croserrate setae terminally; exopod shorter than basis.

Pereopod 1 (Fig. 4E) basis $0.9 \times$ remaining articles combined, with numerous hair-like setae medially, 19 short simple setae on lateral surface, 2 complex pedunculate setae laterodistally, 1 short plumose seta on terminal point; ischium $0.1 \times$ basis, with 1 complex pedunculate seta mediodistally; merus $1.7 \times$ ischium, with 1 complex pedunculate seta mediodistally; carpus $1.6 \times$ merus, with 1 short simple seta mediodistally; propodus subequal to carpus, with 6 simple setae medially; dactylus $0.9 \times$ propodus, with 9 simple setae medially, 1 short simple and 2 simple setae terminally; exopod shorter than basis. 


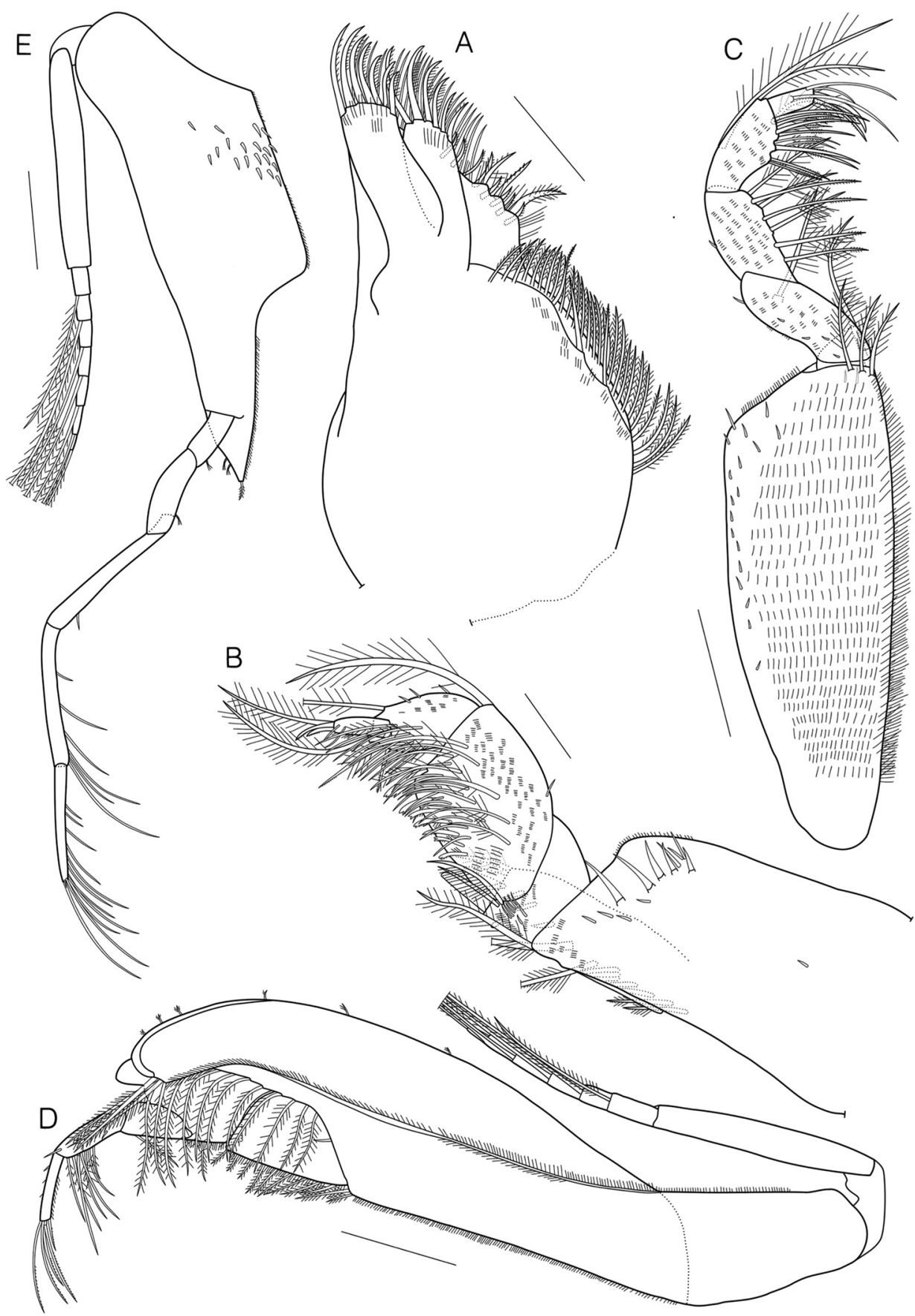

Figure 4. Eocuma orbiculatum sp. nov., holotype, adult male, $11.92 \mathrm{~mm}$. A Maxilla 2 B maxilliped 1 C maxilliped $2 \mathbf{D}$ maxilliped $3 \mathbf{E}$ pereopod 1. Scale bars: $0.3 \mathrm{~mm}(\mathbf{D}, \mathbf{E}), 0.2 \mathrm{~mm}(\mathbf{C}), 0.1 \mathrm{~mm}(\mathbf{A}, \mathbf{B})$. 
Pereopod 2 (Fig. 5A) length $0.3 \times$ basis of pereopod 1 , basis fused with ischium, $0.6 \times$ remaining articles combined, with 2 long plumose and 1 complex pedunculate setae medially, 3 complex pedunculate setae on lateral surface, 7 complex pedunculate setae and 1 short simple seta with subterminal setules laterally; merus $0.4 \times$ basis, with 1 short simple seta with subterminal setules mediodistally, 1 short simple seta with subterminal setules lateroproximally; carpus $0.6 \times$ merus, with 1 short simple seta with subterminal setules laterodistally; propodus $1.4 \times$ carpus, with 1 short simple seta with subterminal setules mediodistally; dactylus $1.5 \times$ propodus, with 1 short simple seta with subterminal setules and 1 broken seta medially, 1 simple seta with terminal setules laterally, 1 plumo-annulate seta, 1 long plumo-annulate seta with single subterminal setule, and 1 simple seta with terminal setules terminally.

Pereopod 3 (Fig. 5B) basis $0.9 \times$ remaining articles combined, with 5 complex pedunculate setae and 2 short simple setae with subterminal setules medially, 6 short simple setae with subterminal setules on lateral surface, 4 long plumose setae laterally; ischium $0.2 \times$ basis, with 2 annulate setae laterodistally; merus $2.7 \times$ ischium, with 2 short simple setae with subterminal setules medioproximally, 1 annulate seta laterally; carpus $0.7 \times$ merus, with 3 annulate setae medially, 1 short simple seta with subterminal setules and 1 annulate seta laterally, 1 short simple and 2 long annulate setae on medial distal margin; propodus $0.7 \times$ carpus, with 1 long annulate seta on medial distal corner, 1 complex pedunculate seta laterodistally; dactylus $0.4 \times$ propodus, with 1 simple and 1 stout microserrate setae terminally.

Pereopod 4 (Fig. 5C) basis $0.9 \times$ remaining articles combined, with 1 plumose and 4 complex pedunculate setae medially, 8 plumose setae and 3 short simple setae with subterminal setules laterally; ischium $0.2 \times$ basis, with 1 short simple seta with subterminal setules laterally, 2 annulate setae on distal margin; merus $2.3 \times$ ischium, with 1 annulate seta laterodistally; carpus $0.7 \times$ merus, with 3 long annulate setae and 1 short simple seta with subterminal setules medially, 1 short simple and 2 long annulate setae on medial distal corner, 1 annulate seta laterally; propodus $0.7 \times$ carpus, with 1 long annulate and 1 complex pedunculate setae mediodistally; dactylus $0.4 \times$ propodus, with 2 simple and 1 stout microserrate setae terminally.

Pereopod 5 (Fig. 5D) basis subequal to remaining articles combined, with 3 long plumose, 9 plumose, 2 complex pedunculate setae, and 2 short simple setae with subterminal setules; ischium $0.2 \times$ basis, with 1 short simple and 2 annulate setae laterodistally; merus $2.0 \times$ ischium, with 1 annulate seta laterally; carpus $0.6 \times$ merus, with 4 annulate setae medially, 1 annulate seta laterally; propodus $0.8 \times$ carpus, with 1 long annulate seta on medial distal corner; dactylus $0.3 \times$ propodus, with 2 simple and 1 stout microserrate setae terminally.

Uropod (Fig. 5E) peduncle $0.4 \times$ pleotelson, with 9-10 plumose, 14-16 stout short simple, and 35-40 microserrate setae medially. Endopod uniarticulate, $3.2 \times$ peduncle, with 21 plumose, 77 plumo-microserrate, and 3 stout short simple setae medially, tip with setulate seta. Exopod biarticulated, subequal to endopod, article 1 unarmed; article 2 with 23 plumose setae medially, 21 plumose setae laterally, 1 simple seta distally, tip with 2 curved setulate setae. 


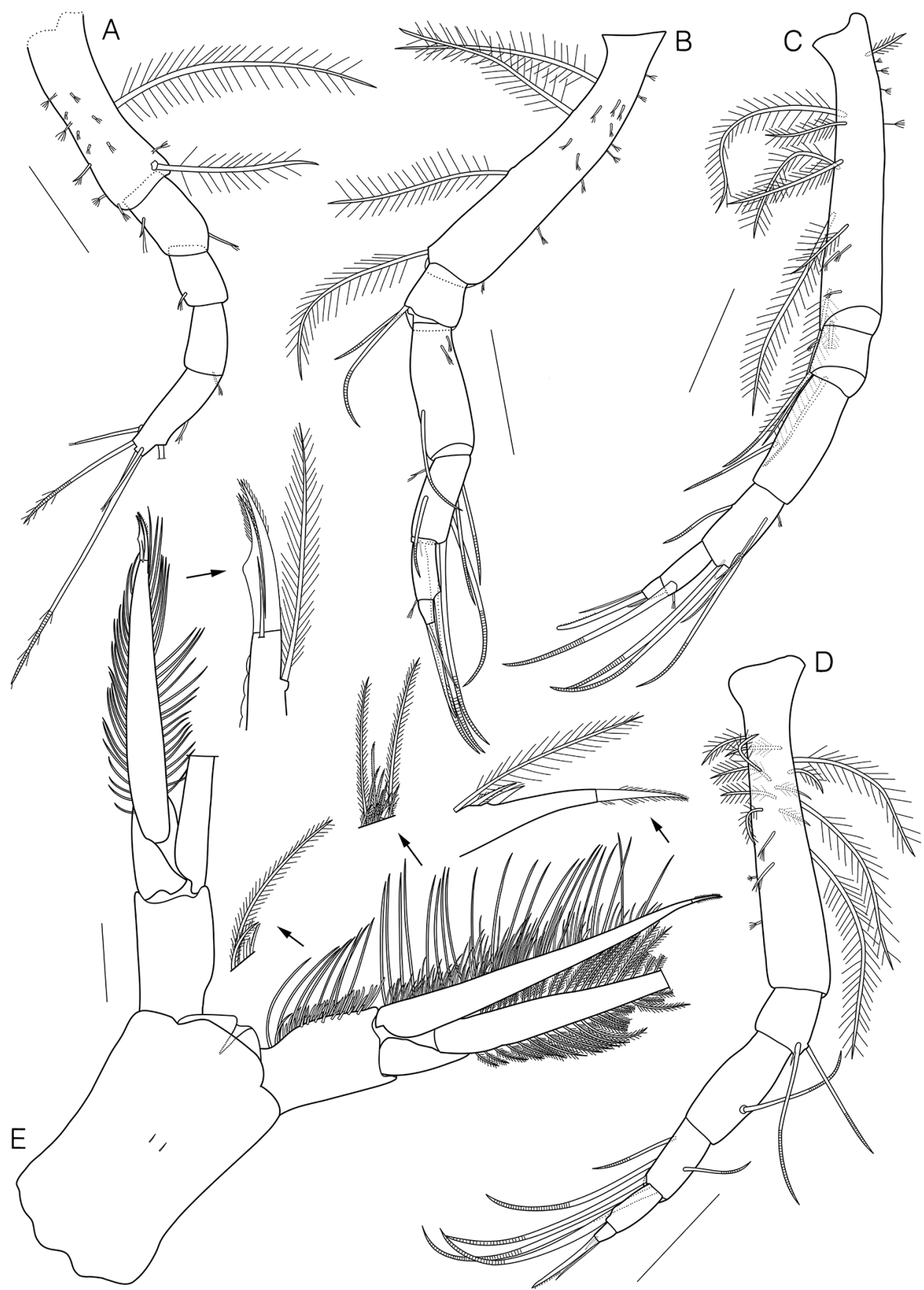

Figure 5. Eocuma orbiculatum sp. nov., holotype, adult male, $11.92 \mathrm{~mm}$. A Pereopod 2 B pereopod 3 C pereopod 4 D pereopod 5 E pleotelson. Scale bars: $0.3 \mathrm{~mm}(\mathbf{E}), 0.2 \mathrm{~mm}(\mathbf{B}-\mathbf{D}), 0.1 \mathrm{~mm}(\mathbf{A})$. 
Remarks. This new species resembles Eocuma amakusense Gamô, 1967, E. hilgendorfi Marcusen, 1894, and E. latum Calman, 1907 in having a pair of well-developed dorso-lateral carinae on the flat carapace and similar setae pattern on the telson. Eocuma orbiculatum sp. nov., however, is easily distinguished from its congeners by the pattern of dorso-lateral carina and lacking lateral horns on the carapace. This difference also applies when considering growth, geographical distribution and individual variations (Table 1). Comparison between the species was done assuming that $E$. orbiculatum sp. $\mathrm{n}$ and $E$. cf. hilgendorfi (by Park et al. 1998) subadult male was the same species, since information of $E$. hilgendorf adult male was not suggested in previous studies. Eocuma orbiculatum sp. $\mathrm{n}$ is distinguished from the specimen of Park et al. (1998) by the combination of the following features (E. cf. hilgendorfi condition in parentheses): 1) a pair of dorso-lateral carinae from near the near apices of the anterolateral horns extending to approximately 0.8 of the carapace length (vs. from ocular lobe to the posterior margin of carapace); 2) carapace without lateral horn (vs. with lateral horns); 3) basis of pereopod 1 with 19 short simple setae on ventral surface (vs. without short simple seta); 4) carpus of pereopod $1.6 \times$ merus length (vs. $2.3 \times$ merus length); 5) medial margin of uropod peduncle and endopod with plumose, stout short simple, and microserrate setae (vs. with plumose setae on endopod, with plumose setae and 3 spaced teeth on exopod); 6) uropod exopod with plumose setae laterally (vs. without seta). Even considering growth and individual variations, many differences were found in carapace shape, carpus length, and setal pattern of the telson. In addition, E. cf. hilgendorf (by Park et al. 1998) is considered to be a different species, as it shows many morphological differences from $E$. hilgendorfi reported by Zimmer (1903). Additional samples shall be obtained and identified.

Etymology. The new species name orbiculatum is a Latin word, meaning 'round', alluding to the absence of a horn on the lateral margin of the carapace and the round appearance of the carapace in dorsal view.

Distribution. The new species was collected in Hangdong Port, Sedong-ri, Wando-gun, Jeollanam-do, Korea, muddy bottom, 2-5 m depth.

\section{Key to the Korean Eocuma species}

1 Carapace lacking lateral horn; a pair of dorso-lateral carinae extending to approximately 0.8 of the carapace length .....................E. orbiculatum sp. nov.

- Carapace with lateral horn; a pair of dorso-lateral carinae extending to the posterior margin of carapace ................................................................... 2

2 Carapace, lateral horn obtuse and rounded ........................... E. amakusense

- $\quad$ Carapace, lateral horn prominent and acute............................................. 3

3 Pereopod 1, basis length much longer than remaining articles combined and without short simple setae on lateral surface ...................... E. cf. hilgendorfi

- $\quad$ Pereopod 1 , basis length equal to remaining articles combined and with several short simple setae on lateral surface 
$\frac{\vec{s}}{\pi}$

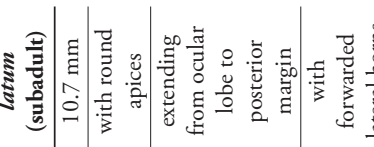

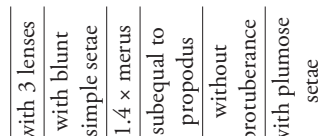

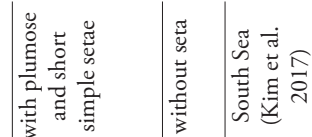

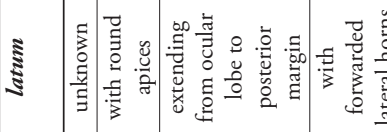

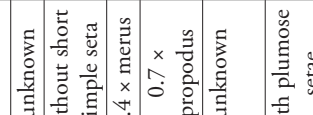

爱

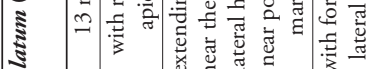

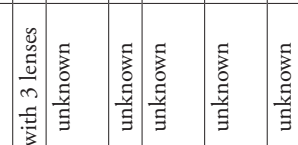

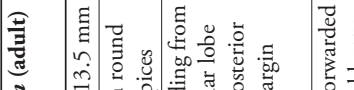

至

एँ

责

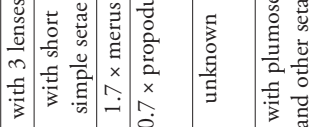

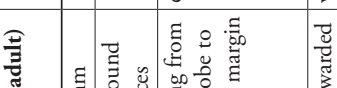

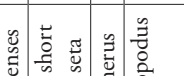

ปิ

\begin{tabular}{|c|c|}
\hline 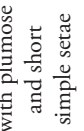 & 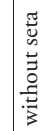 \\
\hline
\end{tabular}

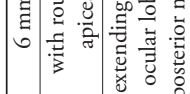

要焉

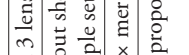

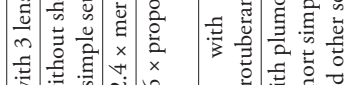

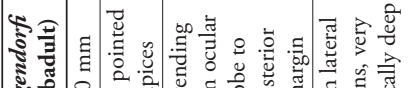

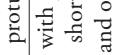

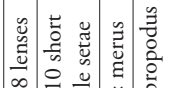

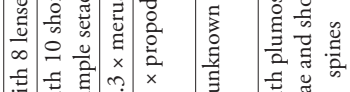

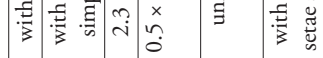

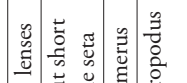

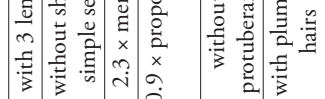

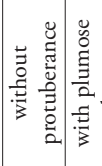

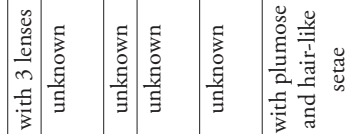

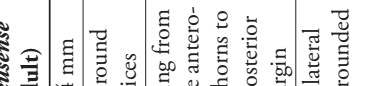

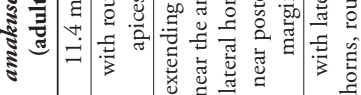

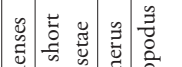

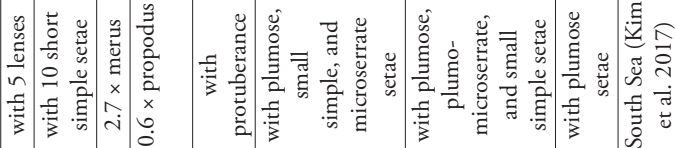

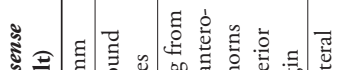

Tु

$\frac{10}{0}$

:

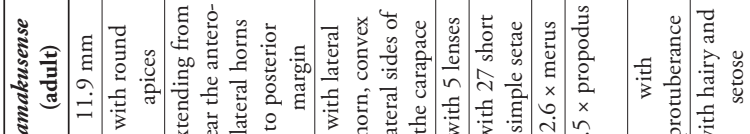

\section{₹}

吾

范

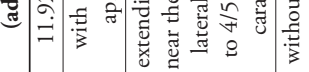

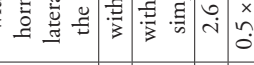

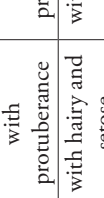

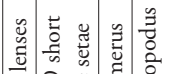

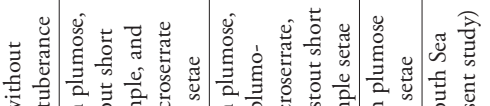

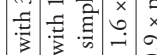

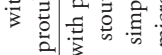

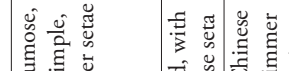

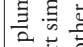

苦劳

ซै

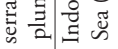

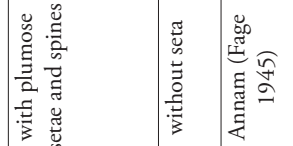

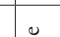

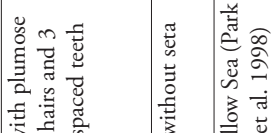

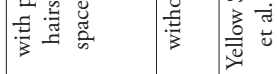

(1)

\begin{tabular}{|c|}
\hline 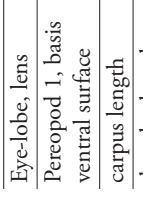 \\
\hline
\end{tabular}

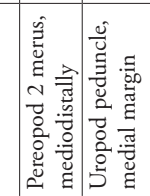

㟥

름

咆




\section{Acknowledgements}

This work was supported by a grant from the National Institute of Biological Resources (NIBR), funded by the Ministry of Environment (MOE) of the Republic of Korea (NIBR No. 201701201).

\section{References}

Bate CS (1856) On the British Diastylidae. The Annals and Magazine of Natural History series 2, 17(2): 449-465. https://doi.org/10.1080/00222935608697553

Day J (1978) South African Cumacea Part 2 family Bodotriidae, subfamily Bodotriinae. Annals of the South African Museum 75(7): 159-290.

Fage L (1945) Les Cumacés du plancton nocturne des côtes d'Annam. Archives de Zoologie Expérimentale et Générale 84: 165-224. [in French]

Gamô S (1958) On some species of cumacean Crustacea from Sagami Bay. Dobutsugaku Zasshi 67: 383-389.

Gamô S (1963) Review summary on the Order Cumacea, with a list of the species found in Japan. Researches on Crustacea 1: 73-90. https://doi.org/10.18353/rcustacea.1.0_73

Gamô S (1967) Studies on the Cumacea (Crustacea, Malacostraca) of Japan. Part I. Publications of the Seto Marine Biology Laboratory 15: 133-163. https://doi.org/10.5134/175460

Goodsir HDS (1843) Description of the genus Cuma, and of two new genera nearly allied to it. The Edinburgh New Philosophical Journal 34: 119-130.

Haye PA (2007) Systematics of the genera of Bodotriidae (Crustacea: Cumacea). Zoological Journal of the Linnean Society 151: 1-58. https://doi.org/10.1111/j.1096-3642.2007.00322.x

Holmes JMC, O’Connor JP (1988) A portable light-trap for collecting marine crustaceans. Journal of the Marine Biological Association of the United Kingdom 68(2): 235-238. https://doi.org/10.1017/S0025315400052140

Kim IH (1992) Using a light-trap for collecting marine crustaceans. The Newsletter of the Korean Society of Systematic Zoology 16: 6-7. [in Korean]

Kim SH, Lee CH, Kim YH (2017) Two New Records of the Eocuma Species (Crustacea, Cumacea, Bodotriidae) from Korea. Animal Systematics, Evolution and Diversity 33(4): $235-245$.

Liu H, Liu JY (1990) Study on Cumacea (Crustacea Malacostraca) of the offshore waters of north China. Studia Marina Sinica 10(31): 195-228. [in Chinese with summary and species descriptions in English]

Marcusen J (1894) [Untitled "Herr Hilgendorf legte vor eine briefliche Mittheilung des jüngst verstbenen Staatsraths Prof. J. Marcusen in Bern über ein neues Cumaceen Genus Eocuma, Fam. Cumadae, aus Japan.”]. Sitzungs-Berichte der Gesellschaft Naturforschender Freunde zu Berlin 1894: 170-171.

Park MR, Hong JS, Choi KS (1998) The Bodotriid Cumacea (Crustacea: Malacostraca) from the Yellow Sea. Journal of Fisheries Science and Technology 1: 94-112. 
Petrescu I (1998) Cumaceans (Crustacea: Cumacea) collected by the expedition of "Grigore Antipa” National Museum of Natural History from the coasts of Tanzania (1973-1974). Part I. Family Bodotriidae. Travaux du Museum National d'Histoire Naturelle "Grigore Antipa" 40: 227-310.

Sars GO (1865) Om den aberrante Krebsdyrgruppe Cumacea og dens nordiske Arter. Förhandlingar i Videnskabs Selskabet i Christiania 1864: 128-208. [in Norwegian]

Sars GO (1878) Nye Bidrag til Kundskaben om Middelhavets Invertebratfauna. II. Middelhavets Cumaceer. Archiv for Mathematik og Naturvidenskab 3: 461-512. https://doi. org/10.5962/bhl.title.10404 [in Latin and Norwegian]

Scott T (1901) Notes on Scottish cumaceans. Annals of Scottish Natural History 1901: 215224. https://doi.org/10.5962/bhl.title.59822

WoRMS Editorial Board (2019) World Register of Marine Species. http://www.marinespecies.org [Accessed 2019-08-01]

Zimmer C (1903) Die Cumaceen des Museums für Naturkunde in Berlin. Zoologische Jahrbücher, Abtheilung für Systematik, Geographie und Biologie der Thiere 18(6): 664-694.

Zimmer C (1952) Indochinesische Cumaceen. Mitteilungen aus dem Zoologischen Museum in Berlin 28: 7-35. [in German] 